\title{
PLAC1 Expression Decreases in Chorionic Villi in Response to Labor
}

\author{
Yahdira M. Rodriguez-Prado, ${ }^{1}$ Xiaoyuan Kong, ${ }^{1}$ and Michael E. Fant ${ }^{1,2,3}$ \\ ${ }^{1}$ Department of Pediatrics, University of South Florida Morsani College of Medicine, Tampa, FL 33606, USA \\ ${ }^{2}$ Department of Obstetrics and Gynecology, University of South Florida Morsani College of Medicine, Tampa, FL 33606, USA \\ ${ }^{3}$ Department of Pathology and Cell Biology, University of South Florida Morsani College of Medicine, Tampa, FL 33606, USA
}

Correspondence should be addressed to Michael E. Fant; mfant@health.usf.edu

Received 26 March 2013; Accepted 26 May 2013

Academic Editors: A. Martin-Hidalgo and G. Rizzo

Copyright (c) 2013 Yahdira M. Rodriguez-Prado et al. This is an open access article distributed under the Creative Commons Attribution License, which permits unrestricted use, distribution, and reproduction in any medium, provided the original work is properly cited.

PLAC1 (Placenta-Specific 1) is a recently described, trophoblast-expressed gene essential for normal placental development. The protein localizes to the microvillus membrane surface of the syncytiotrophoblast in direct proximity to the maternal compartment. Although its role has not been defined, increased circulating levels of human PLAC1 mRNA in maternal blood are associated with preeclampsia. Furthermore, PLAC1-null mice exhibit decreased viability in the peripartum period suggesting a role in pregnancy maintenance late in gestation. We examined PLAC1 gene expression in the human placenta during normal pregnancy and pregnancies associated with maternal diabetes and preeclampsia using quantitative, real time PCR (q-RT-PCR). Although there was no apparent difference in PLAC1 gene expression among human pregnancies complicated by diabetes or preeclampsia, an unexpected effect of labor was noted at term. PLAC1 expression in placentae delivered vaginally following induced or spontaneous labor was significantly reduced compared to placentae not exposed to labor making it one of only a few placental genes influenced by labor. The significance of this finding is unknown. Viewed in the context of its importance in placental development, however, these findings are consistent with a role for PLAC1 in the maintenance of the maternal-fetal interface.

\section{Introduction}

PLAC1 is a recently identified X-linked gene [1]. Compared to normal adult tissues, its expression is restricted primarily to cells of trophoblast lineage. The putative PLAC1 protein contains a signal peptide and a ZP3 motif (zona pellucida 3) suggesting it targets the secretory pathway and likely interacts with other membrane-associated proteins [2,3]. Subsequent studies have confirmed its localization to the maternal surface of the syncytiotrophoblast, placing it in direct contact with the maternal compartment, suggesting it may be involved in protein interactions at the maternal-fetal interface [4].

Several studies have identified PLAC1 as a potential biomarker for gestational pathologies relevant to human health. Farina et al. (2005) first demonstrated that circulating PLAC1 mRNA in maternal blood was diminished in pregnancies associated with threatened abortion prior to 20 weeks gestation [5]. Subsequently, elevated levels of circulating PLAC1 mRNA were observed in pregnancies complicated by preeclampsia and were directly related to disease severity [6, 7]. Recently, we reported that women can become sensitized to the PLACl antigen during pregnancy and the presence of anti-PLAC1 antibodies may be associated with infertility and/or recurrent pregnancy loss [8]. This observation was later supported by Matteo et al. who demonstrated increased titers of anti-PLAC1 antibodies in women with a history of infertility [9].

Using a mutant mouse model we have recently confirmed that PLAC1 is essential for normal placental development. The absence of $P L A C 1$ results in marked placentomegaly and mild intrauterine growth retardation indicating some degree of placental insufficiency [10]. While the PLAC1 knockout (KO) is not lethal, it is associated with decreased viability. The distribution of genotypes among viable prenatal and postnatal 
progeny indicates that something occurs late in gestation to increase the probabilistic risk of perinatal death. Collectively, these observations suggest that PLAC1 contributes, in part, to regulatory processes at the maternal-fetal interface and may be particularly important for fetal survival late in gestation and/or during parturition. We therefore sought to examine PLAC1 expression during human gestation in the presence or absence of common gestational disorders associated with adverse fetal outcomes.

\section{Materials and Methods}

2.1. Study Subjects. Placental tissue was collected from women delivered at Memorial Hermann Hospital (Houston, Texas) and Tampa General Hospital (Tampa, FL) under protocols approved by the Institutional Review Boards of the University of South Florida and the University of TexasHouston Medical School in accordance with the Code of Ethics of the World Medical Association (Declaration of Helsinki) for experiments involving humans. Initially, placental samples were obtained at various gestational ages from normal pregnancies or those complicated by the clinical diagnoses of diabetes and/or preeclampsia. Although preterm pregnancies are inherently not normal, "control" pregnancies throughout gestation were defined as the absence of known maternal disease, intrauterine growth restriction (IUGR), congenital anomalies, multiple gestations, chromosomal defects, and clinical chorioamnionitis.

Subsequently, placental samples were obtained to specifically examine the effects of labor on PLAC1 expression. Samples were obtained from normal, term human placentae (38-41 weeks gestation) immediately after delivery by elective $\mathrm{C} / \mathrm{S}$ (in the absence of labor) or vaginally (in the presence of labor). Labor was further delineated into groups associated with the spontaneous onset of labor (SVD) and induced labor (IVD). Exclusion criteria for these patients included multiple births, diabetes, intrauterine growth retardation, preeclampsia, hypertension, diabetes, autoimmune disease, placental insufficiency, and infection.

2.2. Tissue Collection. A total of $3 \times 0.5 \mathrm{~cm}$. samples were obtained from different sites in each placenta (near the umbilical cord, at the periphery and midway between these two points) and pooled. Samples were rinsed in PBS to remove maternal blood, placed in RNAlater (Ambion/Life Technologies, Carlsbad, CA), and stored at $-20^{\circ} \mathrm{C}$ until RNA isolation.

2.3. Quantitative, Real-Time PCR. After disruption and homogenization of tissue specimens, total RNA was extracted using the AllPrep DNA/RNA Mini Kit (Qiagen, Valencia, CA). $2 \mu \mathrm{g}$ of total RNA was used to synthesize the complementary cDNA with primer oligo dT and the SuperScript III First-Strand Synthesis SuperMix (Invitrogen/Life Technologies, Carlsbad, CA) according to the manufacturer's protocol. The RT-PCR reaction was performed using $2 \mu \mathrm{L}$ cDNA with $1 \mu \mathrm{L} 20 \mathrm{X}$ Taqman Human PLAC1 probe (Assay ID number Hs00222307_ml) (Life Technologies, Carlsbad, CA),

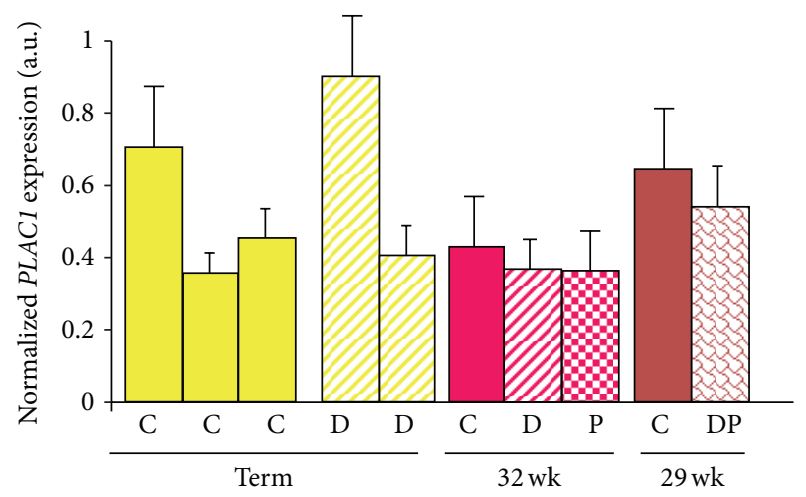

FIgURE 1: PLAC1 mRNA expression in placentae associated with normal and abnormal pregnancies. PLAC1 mRNA expression was measured by quantitative, real-time PCR and normalized to $18 \mathrm{~S}$ ribosomal RNA. Each bar represents the mean + SD (standard deviation) of triplicate samples obtained from a single placenta. Each sample was run in triplicate. $\mathrm{C}=$ normal pregnancy; $\mathrm{D}=$ maternal diabetes; $\mathrm{P}=$ preeclampsia; $\mathrm{DP}=$ presence of both diabetes and preeclampsia.

$10 \mu \mathrm{L}$ TaqMan Universal PCR Master Mix (Life Technologies, Carlsbad, CA) and $7 \mu \mathrm{L}$ autoclaved RNAse-free water for a total volume of $20 \mu \mathrm{L}$. As an internal control, a second RTPCR reaction was performed using $2 \mu \mathrm{L}$ of a $1: 10$ diluted cDNA with $1 \mu \mathrm{L} 20 \mathrm{X}$ Taqman $18 \mathrm{~S}$ probe (Assay ID number Hs99999901_s1) (Life Technologies, Carlsbad, CA). $10 \mu \mathrm{L} 2 \mathrm{X}$ Master Mix and $7 \mu \mathrm{L}$ autoclaved RNAse-free water for a total volume of $20 \mu \mathrm{L}$. Thermocycling conditions were as follows: $50^{\circ} \mathrm{C}, 2 \mathrm{~min} ; 95^{\circ} \mathrm{C}, 10 \mathrm{~min}$; and 40 cycles of $95^{\circ} \mathrm{C}$ for $15 \mathrm{~s}$ and $60^{\circ} \mathrm{C}$ for $1 \mathrm{~min}$. Human PLAC1 mRNA expression relative to $18 \mathrm{~S}$ ribosomal RNA was calculated. Each sample was run in triplicate.

2.4. Statistical Analyses. Statistical analyses were performed using analysis of variance (ANOVA) and the independent $t$ test.

\section{Results}

Preliminary examination of placentae obtained at various gestational ages revealed no discernable effect of diabetes or preeclampsia on PLAC1 expression (Figure 1). However, higher PLAC1 expression was noted in one control and one diabetic placenta at term compared to the other age-matched control and diabetic placentae. Review of the clinical history associated with each placenta revealed that the control and diabetic placentae expressing higher levels of PLAC1 were delivered via scheduled C-section (in the absence of labor) suggesting that $P L A C 1$ expression may be influenced by labor.

In order to examine the possibility that PLAC1 expression was influenced by labor we obtained placental tissue from uncomplicated term pregnancies that delivered in the presence or absence of labor. Placentae assigned to each group (C/S, SVD, IVD) were associated with pregnancies that did not differ significantly in gestational age, birth weight, or Apgar scores (Table 1). As shown in Figure 2, PLAC1 mRNA 


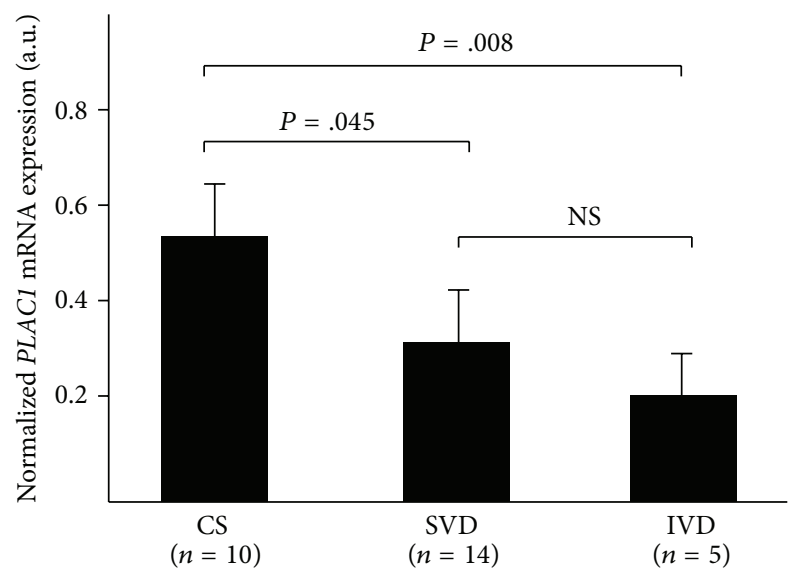

FIGURE 2: PLAC1 mRNA expression in chorionic villi is influenced by the presence of labor. PLAC1 mRNA expression was measured by quantitative, real-time PCR and expressed as a function of $18 \mathrm{~S}$ ribosomal RNA. PLAC1 expression is significantly lower in placentae delivered vaginally after the spontaneous onset of labor (SVD) or induced labor (IVD) compared to placentae delivered via elective $\mathrm{C} / \mathrm{S}$ in the absence of labor. Error bars = standard deviation; NS = not significant.

TABLE 1: Characteristics of study groups.

\begin{tabular}{lccc}
\hline & SVD & IVD & C/S \\
\hline Number & 14 & 5 & 10 \\
Gestational age (weeks) & 38.8 & 40 & 39.1 \\
Birth weight (gm) \pm SD & $3256 \pm 363$ & $3416 \pm 740$ & $3338 \pm 489$ \\
Apgar-1 min & 9 & 8.2 & 8.9 \\
Apgar-5 min & 9 & 9 & 9 \\
$\begin{array}{l}\text { Duration of rupture } \\
\text { (min) } \pm \text { SD }\end{array}$ & $386 \pm 350$ & $701 \pm 1293$ & 1 \\
\hline
\end{tabular}

SD: standard deviation.

expression was significantly lower in placentae delivered vaginally after the spontaneous (SVD) or induced (IVD) onset of labor compared to placentae delivered via elective $\mathrm{C} / \mathrm{S}$ in the absence of labor. Statistical analyses indicated a highly significant difference between $\mathrm{C} / \mathrm{S}$ deliveries and either SVD or IVD, but no difference in expression between the SVD and IVD groups.

\section{Discussion}

We have examined the expression of PLAC1 gene expression during normal human pregnancies and pregnancies associated with maternal diabetes and preeclampsia. Although no significant associations with maternal diabetes or preeclampsia were observed, we were able to demonstrate that its expression is attenuated in response to labor. Previous studies have attempted to identify changes in placental gene expression during labor. A gene expression profile representing 24,650 human genes and 37,123 gene transcripts found 92 placental genes to be downregulated and 94 genes to be upregulated by labor. However, none of these genes was differentially expressed to a significant degree, that is, greater than 2-fold [11]. More recently, Lee et al. [12] found 351 transcripts to be differentially expressed in the vaginal delivery group compared to nonlabored, $\mathrm{C} / \mathrm{S}$ group. Of these genes, 344 genes were upregulated and only 7 were downregulated. The affected genes tended to represent functions related to oxidative stress, angiogenesis, and cell death. As indicated by the above studies, the total number of placental genes influenced by labor comprises an extremely small percentage of the total number of expressed genes supporting the notion that the reduced PLAC1 expression reflects its important role in pregnancy maintenance and/or parturition. Alternatively, it may simply reflect a nonspecific response to the inflammation, oxidative stress, or hypoperfusion associated with labor. These possibilities seem less likely due to the lack of evidence pointing to a more global disruption of gene expression.

Insights into potential transcriptional mechanisms involved in reduced PLAC1 expression are offered by studies demonstrating that PPAR- $\alpha, \delta, \gamma$ and RXR- $\alpha$ expression by placenta and choriodecidua are influenced by labor $[13,14]$. The implications of these findings are compelling given the importance of PPARs and RXR- $\alpha$ to placental development and uterine quiescence $[15,16]$. The relevance of labor-associated changes in PPAR and RXR- $\alpha$ expression to PLAC1 was provided by Chen et al. [17]. Two PLAC1 promoters were identified that utilize RXR/LXR to drive PLAC1 expression. PPARs form heterodimers with RXR- $\alpha$. It is possible that altered RXR/PPAR expression occurring in response to labor influences PLAC1 expression at the transcriptional level. However, this remains to be validated experimentally.

In summary we have shown that $P L A C 1$, a gene essential for normal placental development, is one of only a few placental genes exhibiting reduced expression during labor. These studies do not necessarily implicate PLAC1 in the initiation of labor or parturition and a specific link should be viewed cautiously. However, they are consistent with a role for PLACl in regulating syncytiotrophoblast function at its apical, maternal-facing membrane surface. The physiological significance of this observation will be clarified as the protein interactions that underlie the mechanism of PLACl action are delineated in future studies.

\section{Conclusions}

PLAC1 gene expression is significantly decreased after the onset of labor in the human placenta. The significance of this observation is not yet known. However, its robust expression by cells of trophoblast lineage, its requirement for normal placental development, and the paucity of other placental genes affected by labor are consistent with the hypothesis that PLAC1 acts at the apical surface of the syncytiotrophoblast to support regulatory processes relevant to the maintenance of the maternal-fetal interface. The basis for the interaction between labor and PLAC1 expression awaits further studies.

\section{Acknowledgments}

The authors would like to acknowledge Drs. Terri Ashmeade, Thora Steffenson, and Valerie Whiteman for their valuable 
suggestions during the course of this work. The assistance of Dr. Jane Carver, Ph.D., in the statistical analysis is also acknowledged. This work was supported by a grant from the March of Dimes (no. 09-503, MEF).

\section{References}

[1] M. Cocchia, R. Huber, S. Pantano et al., "PLAC1, an Xq26 gene with placenta-specific expression," Genomics, vol. 68, no. 3, pp. 305-312, 2000.

[2] L. Jovine, W. G. Janssen, E. S. Litscher, and P. M. Wassarman, "The PLAC1-homology region of the $\mathrm{ZP}$ domain is sufficient for protein polymerisation," BMC Biochemistry, vol. 7, article 11, 2006.

[3] C. Bökel, A. Prokop, and N. H. Brown, "Papillote and piopio: drosophila ZP-domain proteins required for cell adhesion to the apical extracellular matrix and microtubule organization," Journal of Cell Science, vol. 118, no. 3, pp. 633-642, 2005.

[4] M. E. Fant, H. Barerra-Saldana, W. Dubinsky, B. Poindexter, and R. Bick, "The PLAC1 protein localizes to membranous compartments in the apical region of the syncytiotrophoblast," Molecular Reproduction and Development, vol. 74, no. 7, pp. 922929, 2007.

[5] A. Farina, N. Rizzo, M. Concu et al., "Lower maternal PLAC1 mRNA in pregnancies complicated with vaginal bleeding (threatened abortion $<20$ weeks) and a surviving fetus," Clinical Chemistry, vol. 51, no. 1, pp. 224-227, 2005.

[6] Y. Purwosunu, A. Sekizawa, A. Farina et al., "Cell-free mRNA concentrations of CRH, PLAC1, and selectin-P are increased in the plasma of pregnant women with preeclampsia," Prenatal Diagnosis, vol. 27, no. 8, pp. 772-777, 2007.

[7] N. Fujito, O. Samura, N. Miharu, M. Tanigawa, M. Hyodo, and Y. Kudo, "Increased plasma mRNAs of placenta-specific 1 (PLAC1) and glial cells-missing 1 (GCM1) in mothers with preeclampsia," Hiroshima Journal of Medical Sciences, vol. 55, no. 1, pp. 9-15, 2006.

[8] A. Kotto-Kome, C. Silva, V. Whiteman, X. Kong, and M. E. Fant, "Circulating anti-PLAC1 antibodies during pregnancy and in women with reproductive failure: a preliminary analysis," ISRN Immunology, vol. 2011, Article ID 530491, 5 pages, 2011.

[9] M. Matteo, P. Greco, P. E. Levi Setti et al., "Preliminary evidence for high anti-PLAC1 antibody levels in infertile patients with repeated unexplained implantation failure," Placenta, vol. 34, no. 4, pp. 335-339, 2013.

[10] S. M. Jackman, X. Kong, and M. Fant, "Plac1 (placenta specific1) is essential for normal placental and embryonic development," Molecular Reproduction and Development, vol. 79, pp. 564-572, 2012.

[11] V. Sitras, R. H. Paulssen, H. Grønaas, Å. Vårtun, and G. Acharya, "Gene expression profile in labouring and nonlabouring human placenta near term," Molecular Human Reproduction, vol. 14, no. 1, pp. 61-65, 2008.

[12] K. J. Lee, S. H. Shim, K. M. Kang et al., "Global gene expression changes induced in the human placenta during labor," Placenta, vol. 31, no. 8, pp. 698-704, 2010.

[13] E. B. E. Berry, R. Eykholt, R. J. A. Helliwell, R. S. Gilmour, M. D. Mitchell, and K. W. Marvin, "Peroxisome proliferator-activated receptor isoform expression changes in human gestational tissues with labor at term," Molecular Pharmacology, vol. 64, no. 6, pp. 1586-1590, 2003.
[14] S. J. Holdsworth-Carson, M. Permezel, C. Riley, G. E. Rice, and M. Lappas, "Peroxisome proliferator-activated receptors and retinoid $\mathrm{X}$ receptor-alpha in term human gestational tissues: tissue specific and labour-associated changes," Placenta, vol. 30, no. 2, pp. 176-186, 2009.

[15] Y. Barak, Y. Sadovsky, and T. Shalom-Barak, "PPAR signaling in placental development and function," PPAR Research, vol. 2008, Article ID 142082, 11 pages, 2008.

[16] V. Sapin, P. Dollé, C. Hindelang, P. Kastner, and P. Chambon, "Defects of the chorioallantoic placenta in mouse RXR $\alpha$ null fetuses," Developmental Biology, vol. 191, no. 1, pp. 29-41, 1997.

[17] Y. Chen, A. Moradin, D. Schlessinger, and R. Nagaraja, "RXR $\alpha$ and LXR activate two promoters in placenta- and tumorspecific expression of PLAC1," Placenta, vol. 32, no. 11, pp. 877884, 2011. 


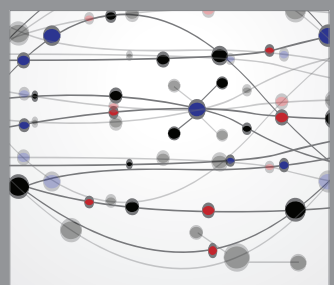

The Scientific World Journal
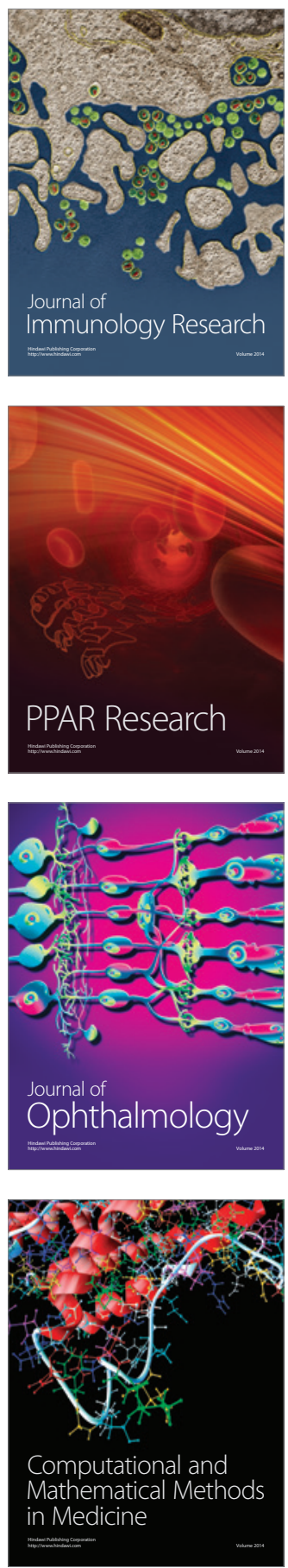

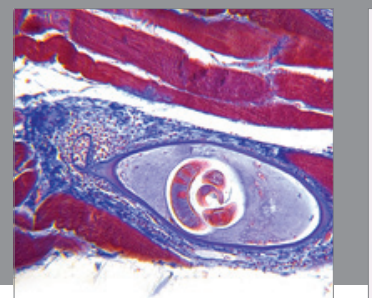

Gastroenterology

Research and Practice
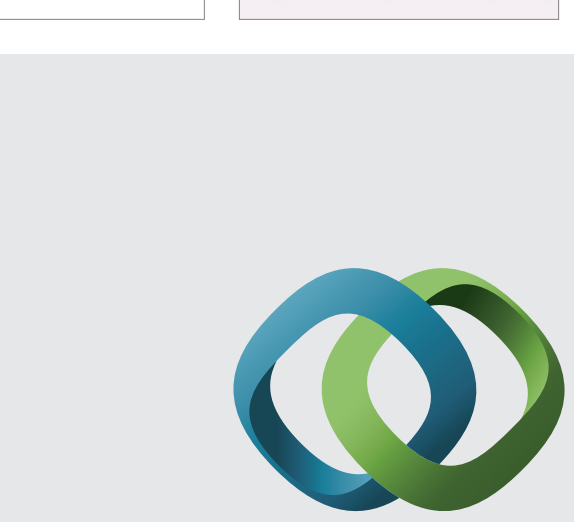

\section{Hindawi}

Submit your manuscripts at

http://www.hindawi.com
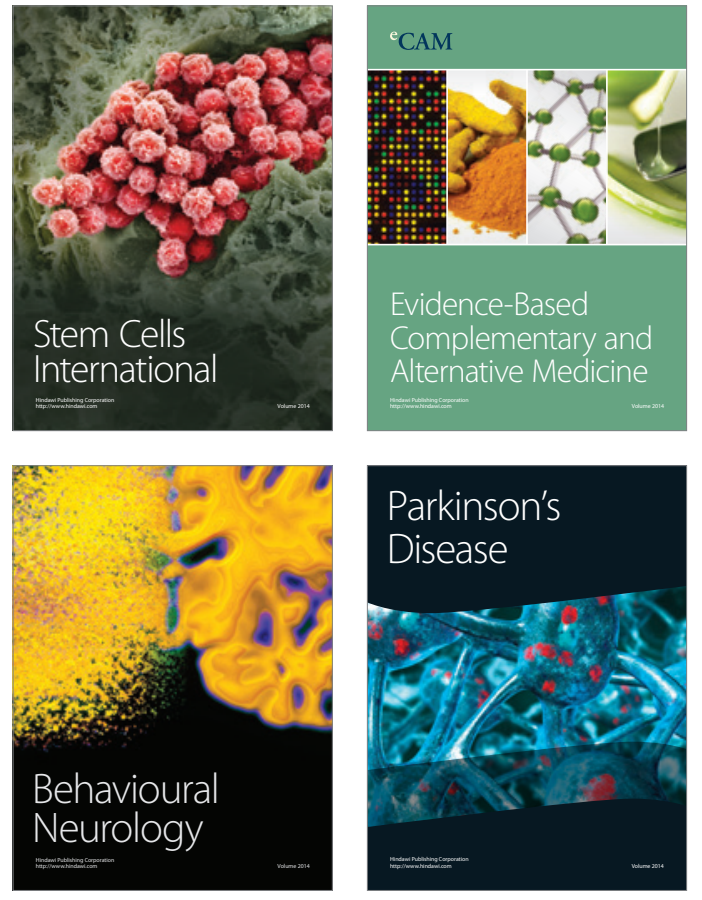
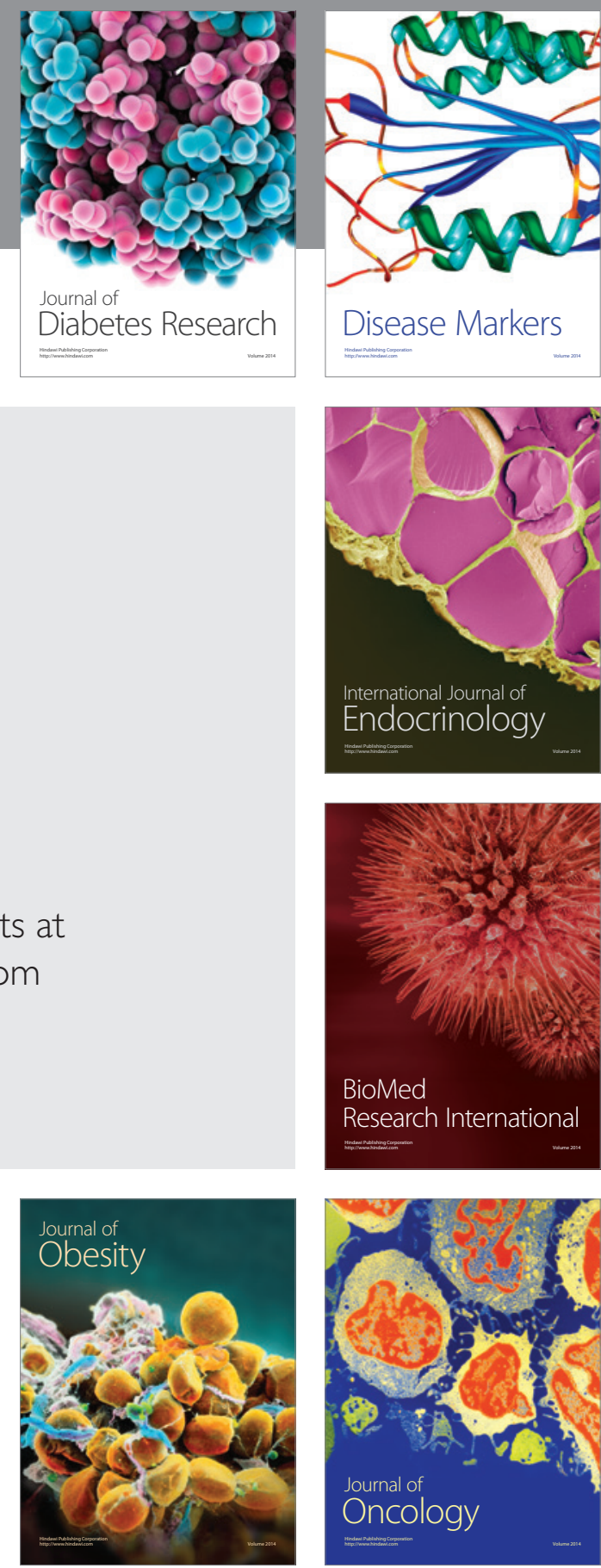

Disease Markers
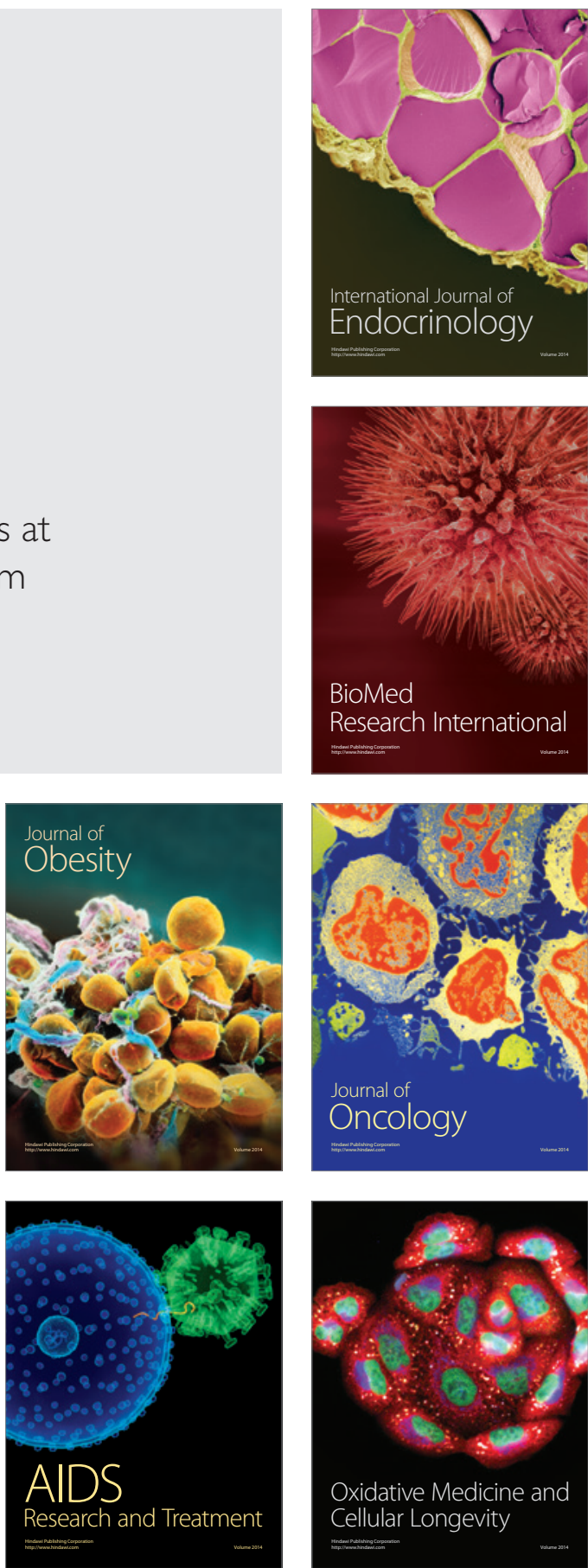